Cerebrovasc Dis 2011;32:616-619

DOI: $10.1159 / 000334579$

\section{Fibrinolytic Treatment of Acute Ischemic Stroke for Patients on New Oral Anticoagulant Drugs}

\section{Carl-Erik Dempflea ${ }^{a}$ Michael G. Hennericib}

Departments of ${ }^{\mathrm{a}}$ Internal Medicine 1 and ${ }^{\mathrm{b}}$ Neurology, Universitätsmedizin Mannheim, University of Heidelberg, Mannheim, Germany

In this issue, Naranjo et al. [1] report on a patient who was offlabel treated with dabigatran $110 \mathrm{mg}$ twice daily after electric cardioversion and developed a large middle cerebral artery (MCA) ischemic stroke after having taken the third dose of dabigatran. Prior to cardioversion, the patient received enoxaparin at an unknown dose for 1 month. No transesophageal echocardiography for exclusion of intracardial thrombi was performed.

Thrombolysis with rtPA was initiated 190 min after onset of symptoms corresponding to approximately $6 \mathrm{~h}$ after the last dose of dabigatran, and the patient developed fatal intracerebral hemorrhage $12 \mathrm{~h}$ later.

In an earlier issue of Cerebrovascular Diseases, De Smedt et al. [2] described the use of rtPA for stroke thrombolysis in another patient with atrial fibrillation treated with dabigatran as participant of the RELY-ABLE study. In this case, rtPA was started $9 \mathrm{~h}$ after the last dose of dabigatran. There were no signs of intracranial hemorrhage in the control CT scan and no other bleeding complications. Matute et al. [3] treated a patient with $\mathrm{rtPA}$ receiving dabigatran $220 \mathrm{mg}$ once daily for prevention of venous thromboembolism after knee surgery, who developed a left MCA ischemic stroke with right-sided hemiplegia and aphasia. The patient had received the last dose of dabigatran $15 \mathrm{~h}$ before treatment with rtPA and there were no hemorrhagic complications. In all three cases, prothrombin time (PT) and activated partial thromboplastin time (aPTT) were essentially normal at the time rPA treatment was started.

The case reported by Naranjo et al. [1] differs from the other two cases in that it is the only one with stroke occurring shortly after cardioversion, the patient had not been on long-term dabigatran treatment, and rtPA was started at a time when relevant plasma concentrations of dabigatran are expected to be present.

Oral direct thrombin inhibitors like dabigatran and factor Xa inhibitors like rivaroxaban, apixaban or edoxaban have a reliable anticoagulant effect without the need of laboratory monitoring or repeated dose adjustments. Extensive clinical trials have demonstrated that these drugs are at least equally effective as vitamin $\mathrm{K}$ antagonists for the prevention of stroke and systemic embolism in patients with atrial fibrillation. Dabigatran at the higher dose of $150 \mathrm{mg}$ twice daily was clearly superior to warfarin [4]. In the RELY study [4], the rate of ischemic or nonspecified stroke was $1.34 \%$ per year for the lower dose and $0.92 \%$ per year for the higher dose of dabigatran, i.e. significantly reduced. The rate of intracranial hemorrhage and especially hemorrhagic stroke was also significantly lower compared to warfarin. Rivaroxaban displayed superiority in the on-treatment analysis; the intention-to-treat analysis demonstrated non-inferiority [5]. Apixaban at a dose of $5 \mathrm{mg}$ twice daily was superior to acetylsalicylic acid in the prevention of stroke and systemic embolism [6] (table 1).

In addition to prevention of stroke and systemic embolism in atrial fibrillation, the novel oral anticoagulant drugs are used for other indications, including prophylaxis and treatment of venous thrombosis and pulmonary embolism. It is to be expected that with more widespread use of the oral direct thrombin or factor Xa inhibitors, clinicians will be increasingly confronted with the question how to treat acute ischemic stroke in these patients.

Fibrinolytic therapy with tPA analogues is approved for treatment of acute ischemic stroke within $3 \mathrm{~h}$ after onset of neurological symptoms and has just been approved within 3-4.5 h according to the results of ECASS3 [7]. This therapy is associated with an increased risk of intracerebral hemorrhage combined with neurological worsening to $7.3 \%$ (range 6.7-7.9) according to the SITS-MOST registry similar to rates in randomized clinical trials [8]. Thus, thrombolytic therapy should be performed in properly equipped, specialized stroke centers and only in patients who meet strict inclusion and exclusion criteria. Patients developing stroke despite vitamin $\mathrm{K}$ antagonist therapy are generally excluded from fibrinolytic therapy because of the increased risk of bleeding imposed by low levels of vitamin-K-dependent coagulation factors regardless of the international normalized ratio (INR) [9]. On the other hand, rapid reversal of the anticoagulant effect by prothrombin complex concentrates is not recommended, presumably due to an anticipated thromboembolic risk.

The new oral anticoagulant drugs currently studied in large randomized clinical trials (table 1) differ from warfarin and the other vitamin $\mathrm{K}$ antagonists in that they do not reduce the levels of coagulation proenzymes but directly inhibit the active procoagulant enzymes thrombin or factor Xa. This inhibitory effect is directly dependent upon the plasma concentration of the active drug. After ingestion of the drug, maximal plasma levels are attained within approximately $1-2 \mathrm{~h}$, followed by a continuous decline.

Some considerations concerning fibrinolytic therapy in patients treated with thrombin or factor Xa inhibitors: tPA does not directly degrade fibrin but activates endogenous plasminogen, which then degrades the fibrin. Fibrin acts as cofactor in tPAinduced plasminogen activation [12], resulting in a 1,000-fold enhancement of the plasminogen activation rate in the presence of fibrin, compared to fibrinogen [13]. Enhancement of tPA-in-

\section{KARGER}

Fax +41613061234 E-Mail karger@karger.ch www.karger.com
(อ) 2011 S. Karger AG, Basel

$1015-9770 / 11 / 0326-0616 \$ 38.00 / 0$ 
Table 1. New oral anticoagulant drugs

\begin{tabular}{llrl}
\hline Drug & Study acronym & Patients & Status \\
\hline Dabigatran 110 mg/150 mg b.i.d. versus warfarin INR 2-3 & RELY & 18,113 & published [4] \\
Rivaroxaban 20 mg q.d. versus warfarin INR 2-3 & ROCKET-AF & 14,264 & published [5] \\
Apixaban 5 mg b.i.d. versus warfarin INR 2-3 & ARISTOTLE & 18,205 & published [10] \\
Apixaban 5 mg b.i.d. versus aspirin 81-324 mg o.d. & AVERROES & 5,599 & published [6] \\
Edoxaban 30 mg/60 mg q.d. versus warfarin INR 2-3 & ENGAGE-AF & 20,500 & ongoing [11] \\
\hline
\end{tabular}

duced plasminogen activation requires binding of both tPA and plasminogen to specific binding sites on fibrin, which are generated by conformational changes occurring upon conversion from fibrinogen to fibrin $[14,15]$. Fibrinogen is largely inert, limiting the action of tPA (endogenous as well as therapeutically applied) to fibrin [13, 16-19]. This fibrin dependency applies not only to endogenous tPA, which is continuously released by the endothelium, but also to therapeutically applied tPA and tPA analogues.

During fibrin degradation, more binding sites for tPA and plasminogen are formed by exposure of C-terminal lysine residues at plasmin cleavage sites, leading to a positive feedback in plasminogen activation and fibrin degradation [20]. These additional binding sites are eliminated by thrombin-activated fibrinolysis inhibitor (TAFIa)

TAFIa is an antifibrinolytic enzyme activated from the proenzyme form TAFI by thrombin bound to thrombomodulin [21, 22], and also by plasmin [23]. TAFIa reduces the cofactor effect of fibrin in tPA-induced plasminogen activation and limits further proteolysis by plasmin [24]. Direct thrombin and factor Xa inhibitors have been shown to reduce the amount of TAFIa formed, thereby enhancing the proteolysis of fibrin clots $[25,26]$.

$\alpha_{2}$-Antiplasmin is the main inhibitor of plasmin in blood [27] and is covalently linked to fibrin $[16,28-30]$ by factor XIIIa. Fibrin-bound $\alpha_{2}$-antiplasmin renders the fibrin more resistant towards plasmin proteolysis [31]. Factor XIII is activated by thrombin and inhibition of thrombin by direct thrombin inhibitors [32], or the inhibition of thrombin generation by direct factor Xa inhibitors reduces the amount of factor XIIIa generated, and thus, the amount of $\alpha_{2}$-antiplasmin attached to the fibrin clot. This also results in a profibrinolytic effect of anticoagulant drugs.

Finally, tPA-induced plasminogen activation is dependent upon clot permeability (influencing the motion of tPA and plasminogen within the clot) and the availability of binding sites for both tPA and plasminogen. Clot permeability is strongly influenced by thrombin activity. A high thrombin concentration results in reduced clot permeability, and thus, further increases the resistance of the clots towards fibrinolysis. Anticoagulant drugs, including the direct thrombin and factor $\mathrm{Xa}$ inhibitors increase the porosity of fibrin clots [32]. In the experiments of Blombäck et al. [32], this effect was more pronounced at therapeutic levels of direct thrombin and factor Xa inhibitors than at therapeutic levels of vitamin $\mathrm{K}$ antagonists. According to the results of Ammollo et al. [25], clots generated in the presence of dabigatran were more permeable, less rigid and consisted of thicker fibers. In fibrin clots, plasmin appears to move laterally across fibers, the rate of lysis being faster for clots made up of thicker fibers than for clots consisting of thinner fibers [20]. The individual contribution of these mechanisms concerning the outcome of fibrinolytic therapy needs to be further investigated.

Potential profibrinolytic effects of direct thrombin and factor Xa inhibitors

- Reduction of TAFIa formation

- Reduction of $\alpha_{2}$-antiplasmin attached to fibrin clot

- Enhanced clot permeability

It is to be expected that clots developing in the presence of dabigatran, rivaroxaban, apixaban, edoxaban or other direct thrombin or factor $\mathrm{Xa}$ inhibitors are more responsive to fibrinolytic therapy. This may result in increased risk of intracranial hemorrhage associated with fibrinolytic therapy, although it is a matter of speculation if the anticoagulant drug needs to be present already during clot formation to cause the effect or if presence of the drug during fibrinolysis is sufficient.

An enhanced profibrinolytic effect leading to a drop in plasma fibrinogen levels due to plasmin proteolysis [33], or to increased levels in fibrinogen degradation products [34], has been shown to be associated with an increased rate of intracranial hemorrhage during rtPA treatment.

Vitamin $\mathrm{K}$ antagonists can rapidly be antagonized by prothrombin complex concentrates, but this may induce a procoagulant response. Consequently, ongoing treatment with vitamin $\mathrm{K}$ antagonists is considered a contraindication for fibrinolytic therapy with rtPA. The anticoagulant effect of the new direct thrombin and factor Xa inhibitors is dependent upon plasma concentration, and depending upon the pharmacokinetics, the anticoagulant effect disappears within 12-24 h after ingestion of the drug. At present, laboratory assays for measurement of the specific anticoagulant effects are not yet widely available but should be performed in all patients known or suspected to be on treatment with new anticoagulants before rtPA is administered, similarly to prothrombin time/INR measurement in patients on warfarin treatment.

Thrombin inhibitors [35], as well as factor Xa inhibitors [36], have an effect on coagulation assays like PT and aPTT, but this effect is highly variable, depending on the reagent and laboratory instrument used for measurement [36, 37]. Although these assays may be used for detecting a possible overdose, levels within the lower therapeutic range are not accurately detected.

Direct thrombin inhibitors, such as dabigatran, strongly influence thrombin time. A normal-range thrombin time assay ex- 
cludes the presence of relevant plasma concentrations of dabigatran. For accurate determination of dabigatran plasma levels, the thrombin time assay needs to be modified, and specific dabigatran calibrators are needed. Direct factor Xa inhibitors do not influence thrombin time but have a strong effect on antifactor Xa assays similar to those used for monitoring of low-molecularweight heparin or fondaparinux therapy [38, 39]. Again, drugspecific calibrators are needed for determination of plasma concentration of the drugs, and the reference curves used for lowmolecular-weight heparins cannot be used [40].

In emergency situations, such as the occurrence of acute neurological symptoms in patients treated with dabigatran, rivaroxaban, apixaban, edoxaban or other direct thrombin or factor Xa inhibitors, thrombin time (for thrombin inhibitors) or an antifactor Xa assay (for direct factor Xa inhibitors) should be performed before invasive procedures, such as surgery or fibrinolytic therapy.

Concerning the case report of Naranjo et al. [1], it needs to be mentioned that cardioversion is associated with a relevant risk of embolic stroke, and pretreatment with anticoagulant drugs in the therapeutic dose range is recommended. The authors neither mention the dose of enoxaparin given before cardioversion nor was transesophageal echocardiography performed prior to cardioversion to exclude the presence of atrial thrombi. In a subgroup analysis of the RELY study patients had been treated with a study drug (dabigatran or warfarin) for at least 3 weeks before performing cardioversion. The study protocol recommended against cardioversion of patients with left atrial thrombus [4]. Stroke and systemic embolism rates at 30 days were $0.8 \%$ for dabigatran $110 \mathrm{mg}$ twice daily, $0.3 \%$ for dabigatran $150 \mathrm{mg}$ twice daily, and $0.6 \%$ for warfarin (dabigatran $110 \mathrm{mg}$ vs. warfarin, $\mathrm{p}=$ 0.71 ; dabigatran $150 \mathrm{mg}$ vs. warfarin, $\mathrm{p}=0.40$ ) [41]. Consequently, the case can only be interpreted with caution concerning the possible relation between fibrinolytic therapy performed at a time when a therapeutic level of dabigatran must have been present as well as a possibly spontaneous occurrence of intracranial hemorrhage as the result of a large MCA territory ischemia and tPA treatment.

\section{Summary}

Fibrinolytic therapy with rtPA in patients with dabigatran, and presumably also in patients treated with other novel oral anticoagulant drugs such as rivaroxaban, apixaban or edoxaban, should not be performed when therapeutic plasma levels of anticoagulants are present. As elimination kinetics may vary, depending on renal and hepatic function, body mass and age, measurement of the anticoagulant effect of the drug by functional assays, or measurement of drug levels, must be recommended before attempting rtPA treatment. For direct thrombin inhibitors, thrombin time or related assays provide the most reliable information but take time to become available (approximately $20 \mathrm{~min}$ ). Similarly, for direct factor Xa inhibitors, antifactor Xa assays (chromogenic assays, but also clotting assays) can be used but require specific calibration, as the conventional calibrators based on low-molecular-weight heparin cannot be used.

The novel oral anticoagulant drugs influence PT and aPTT, but the effect is highly variable and a normal range of PT or aPTT does not exclude the presence of relevant concentrations of the anticoagulant in the blood. The PT or INR limits used for estimation of bleeding risk connected to vitamin $\mathrm{K}$ antagonist therapy cannot be applied. Cardioversion in patients treated with the new oral anticoagulant drugs should only be performed after a sufficient phase of reliable anticoagulation and exclusion of intracardial thrombus.

\section{References}

1 Naranjo IC, Portilla-Cuenca JC, Caballero PEJ, Escobar MLC, Sevilla RMR: Fatal intracerebral haemorrhage associated with administration of recombinant tissue plasminogen activator in a stroke patient on treatment with dabigatran. Cerebrovasc Dis 2011;32:614-615.

$\checkmark 2$ De Smedt A, De Raedt S, Nieboer K, De Keyser J, Brouns R: Intravenous thrombolysis with recombinant tissue plasminogen activator in a stroke patient treated with dabigatran. Cerebrovasc Dis 2010;30:533-534.

-3 Matute MC, Guillan M, Garcia-Caldentey J, Buisan J, Aparicio M, Masjuan J, Alonso de Lecinana M: Thrombolysis treatment for acute ischaemic stroke in a patient on treatment with dabigatran. Thromb Haemost 2011;106:178-179.

\4 Connolly SJ, Ezekowitz MD, Yusuf S, Eikelboom J, Oldgren J, Parekh A, Pogue J, et al: Dabigatran versus warfarin in patients with atrial fibrillation. N Engl J Med 2009;361:1139-1151.

5 Patel MR, Mahaffey KW, Garg J, Pan G, Singer DE, Hacke W, Breithardt G, et al: Rivaroxaban versus warfarin in nonvalvular atrial fibrillation. N Engl J Med 2011;365:883-891

-6 Connolly SJ, Eikelboom J, Joyner C, Diener HC, Hart R, Golitsyn S, Flaker $\mathrm{G}$, et al: Apixaban in patients with atrial fibrillation. $\mathrm{N}$ Engl J Med 2011;364:806-817.

7 Hacke W, Kaste M, Bluhmki E, Brozman M, Davalos A, Guidetti D, Larrue V, et al: Thrombolysis with alteplase 3 to $4.5 \mathrm{~h}$ after acute ischemic stroke. N Engl J Med 2008;359:1317-1329.

8 Wahlgren N, Ahmed N, Davalos A, Ford GA, Grond M, Hacke W, Hennerici MG, et al: Intravenous alteplase for acute ischaemic stroke in the Safety Implementation of Thrombolysis in Stroke-Monitoring Study (SITS-MOST): an observational study. Lancet 2007;369:275-282.

9 Cronin CA: Intravenous tissue plasminogen activator for stroke: a review of the ECASS III results in relation to prior clinical trials. J Emerg Med 2010;38:99-105.

10 Granger CB, Alexaner JH, McMurray JJV, Lopes RD, Hylek EM, Hanna M, Al-Khalidi et al: Apixaban versus warfarin in patients with atrial fibrillation. N Engl J Med 2011;365:981-992.

-11 Ruff CT, Giugliano RP, Antman EM, Crugnale SE, Bocanegra T, Mercuri M, Hanyok J, et al: Evaluation of the novel factor Xa inhibitor edoxaban compared with warfarin in patients with atrial fibrillation: design and rationale for the Effective aNticoaGulation with factor xA next GEneration in Atrial Fibrillation-Thrombolysis In Myocardial Infarction study 48 (ENGAGE AF-TIMI 48). Am Heart J 2010;160:635-641.

12 Longstaff C, Thelwell C, Williams SC, Silva MM, Szabo L, Kolev K: The interplay between tissue plasminogen activator domains and fibrin structures in the regulation of fibrinolysis: kinetic and microscopic studies. Blood 2011;117:661-668.

$\checkmark 13$ Hoylaerts M, Rijken DC, Lijnen HR, Collen D: Kinetics of the activation of plasminogen by human tissue plasminogen activator. Role of fibrin. J Biol Chem 1982;257:2912-2919.

14 Yakovlev S, Makogonenko E, Kurochkina N, Nieuwenhuizen W, Ingham K, Medved L: Conversion of fibrinogen to fibrin: mechanism of exposure of tPA- and plasminogen-binding sites. Biochemistry 2000; 39:15730-15741.

15 Nieuwenhuizen W: Fibrin-mediated plasminogen activation. Ann NY Acad Sci 2001;936:237-246

16 Wilhelm SE, Lounes KC, Lord ST: Investigation of residues in the fibrin(ogen) gamma chain involved in tissue plasminogen activator binding and plasminogen activation. Blood Coagul Fibrinolysis 2004; 15:451-461.

17 Mosesson MW: Fibrinogen and fibrin polymerization: appraisal of the binding events that accompany fibrin generation and fibrin clot assembly. Blood Coagul Fibrinolysis 1997;8:257-267. 
18 Medved L, Tsurupa G, Yakovlev S: Conformational changes upon conversion of fibrinogen into fibrin. The mechanisms of exposure of cryptic sites. Ann NY Acad Sci 2001;936:185-204.

19 Haddeland U, Sletten K, Bennick A, Nieuwenhuizen W, Brosstad F: Aggregated, conformationally changed fibrinogen exposes the stimulating sites for t-PA-catalysed plasminogen activation. Thromb Haemost 1996;75:326-331.

20 Weisel JW, Litvinov RI: The biochemical and physical process of fibrinolysis and effects of clot structure and stability on the lysis rate. Cardiovasc Hematol Agents Med Chem 2008;6:161-180.

21 Bajzar L, Nesheim ME, Tracy PB: The profibrinolytic effect of activated protein $\mathrm{C}$ in clots formed from plasma is TAFI-dependent. Blood 1996;88:2093-2100.

-22 Nesheim M, Wang W, Boffa M, Nagashima M, Morser J, Bajzar L: Thrombin, thrombomodulin and TAFI in the molecular link between coagulation and fibrinolysis. Thromb Haemost 1997;78:386-391.

23 Leurs J, Wissing BM, Nerme V, Schatteman K, Bjorquist P, Hendriks D: Different mechanisms contribute to the biphasic pattern of carboxypeptidase U (TAFIa) generation during in vitro clot lysis in human plasma. Thromb Haemost 2003;89:264-271.

24 Foley JH, Cook PF, Nesheim ME: The kinetics of TAFIa-catalyzed cleavage of carboxy terminal lysine residues of fibrin degradation products and removal of plasminogen binding sites. J Biol Chem 2011;286 19280-19286.

-25 Ammollo CT, Semeraro F, Incampo F, Semeraro N, Colucci M: Dabigatran enhances clot susceptibility to fibrinolysis by TAFI-dependent and independent mechanisms. J Thromb Haemost 2010;8:790-798.

26 Nielsen VG, Kirklin JK: Argatroban enhances fibrinolysis by differential inhibition of thrombin-mediated activation of thrombin activatable fibrinolysis inhibitor and factor XIII. Blood Coagul Fibrinolysis 2008;19:793-800

-27 Mutch NJ, Thomas L, Moore NR, Lisiak KM, Booth NA: TAFIa, PAIand alpha-antiplasmin: complementary roles in regulating lysis of thrombi and plasma clots. J Thromb Haemost 2007;5:812-817.

28 Sakata Y, Aoki N: Cross-linking of alpha 2-plasmin inhibitor to fibrin by fibrin-stabilizing factor. J Clin Invest 1980;65:290-297.

-29 Sakata Y, Aoki N: Significance of cross-linking of alpha 2-plasmin inhibitor to fibrin in inhibition of fibrinolysis and in hemostasis. J Clin Invest 1982;69:536-542.

-30 Ichinose A, Tamaki T, Aoki N: Factor XIII-mediated cross-linking of NH2-terminal peptide of alpha 2-plasmin inhibitor to fibrin. FEBS Lett 1983;153:369-371.

-31 Fraser SR, Booth NA, Mutch NJ: The antifibrinolytic function of factor XIII is exclusively expressed through \{alpha\}2-antiplasmin cross-linking. Blood 2011;117:6371-6374.
32 Blombäck M, He S, Bark N, Wallen HN, Elg M: Effects on fibrin network porosity of anticoagulants with different modes of action and reversal by activated coagulation factor concentrate. Br J Haematol 2011;152:758-765.

33 Alonso A, Dempfle CE, Szabo K, Zohsel K, Hennerici MG: Drop of PT Quick percent value is associated with both symptomatic and asymptomatic intracranial hemorrhage in patients treated with rt-PA for acute ischemic stroke. Thromb Res 2011;127:65-66.

- 34 Trouillas P, Derex L, Philippeau F, Nighoghossian N, Honnorat J, Hanss M, Ffrench P, et al: Early fibrinogen degradation coagulopathy is predictive of parenchymal hematomas in cerebral rt-PA thrombolysis: a study of 157 cases. Stroke 2004;35:1323-1328.

- 35 Lindahl TL, Baghaei F, Fagerberg Blixter I, Gustafsson KM, Stigendal L, Sten-Linder M, Strandberg K, et al: Effects of the oral, direct thrombin inhibitor dabigatran on five common coagulation assays. Thromb Haemost 2011;105:371-378.

36 Freyburger G, Macouillard G, Labrouche S, Sztark F: Coagulation parameters in patients receiving dabigatran etexilate or rivaroxaban: two observational studies in patients undergoing total hip or total knee replacement. Thromb Res 2011;127:457-465.

37 Samama MM, Guinet C: Laboratory assessment of new anticoagulants. Clin Chem Lab Med 2011;49:761-772.

-38 Samama MM, Martinoli JL, LeFlem L, Guinet C, Plu-Bureau G, Depasse F, Perzborn E: Assessment of laboratory assays to measure rivaroxaban - an oral, direct factor Xa inhibitor. Thromb Haemost 2010; 103:815-825.

-39 Samama MM, Amiral J, Guinet C, Perzborn E, Depasse F: An optimised, rapid chromogenic assay, specific for measuring direct factor $\mathrm{Xa}$ inhibitors (rivaroxaban) in plasma. Thromb Haemost 2010;104:10781079.

40 Lindhoff-Last E, Samama MM, Ortel TL, Weitz JI, Spiro TE: Assays for measuring rivaroxaban: their suitability and limitations. Ther Drug Monit 2010;32:673-679.

-41 Nagarakanti R, Ezekowitz MD, Oldgren J, Yang S, Chernick M, Aikens TH, Flaker G, et al: Dabigatran versus warfarin in patients with atrial fibrillation: an analysis of patients undergoing cardioversion. Circulation 2011;123:131-136.

Prof. Michael G. Hennerici, MD

Department of Neurology, University of Heidelberg

Universitätsklinikum Mannheim, UMM, Theodor-Kutzer-Ufer 1-3

DE-68167 Mannheim (Germany)

Tel. +49621 383 2885, E-Mail hennerici@neuro.ma.uni-heidelberg.de 